\title{
Introduction to Chapter 6
}

This chapter focuses on the importance of providing training - training of local participants but also the external facilitators who will work with the community - in how to conduct ACM. The authors also argue that capacity building should be seen as part of the ACM process, and training should reflect the ACM approach itself. The chapter acknowledges the degree to which ACM approaches fundamentally differ from much of the training many fieldworkers have received for more conventional field research or extension, and it differs from villagers' more typical experience with outside "developers" or conservationists. It also builds on insights (and gaps) highlighted in Chapters 2 and 3 , as well as the observations and extensive experience of Cronkleton, Evans and Larson.

These authors present three cases from Bolivia, Nicaragua and Ghana in chronological sequence, thereby showing methodological developments in ACM approaches as well as variation necessitated by geographical and contextual difference: They emphasize the importance of reflexivity in learning to help facilitators and community participants to be more conscious of how they learn experientially and the advantages of learning together.

The chapter concludes with specific suggestions for enhancing ACM processes, including encouraging would-be practitioners to "jump into the ACM process and embrace an ethos of experimentation, trial-and-error and learningby-doing." Real understanding tends to come as practitioners implement the iterations of "the worm" (Figure 5.1) and the learning that results. 